\title{
Psychological outcomes of MRSA isolation in spinal cord injury rehabilitation
}

\author{
Jenna L. Gillett $\mathbb{D}^{1} \cdot$ Jane Duff $^{2} \cdot$ Rebecca Eaton $^{2} \cdot$ Katherine Finlay $^{1}$
}

Received: 10 December 2019 / Revised: 24 June 2020 / Accepted: 30 June 2020

(c) The Author(s), under exclusive licence to International Spinal Cord Society 2020

\begin{abstract}
Study design Retrospective secondary analysis with a quantitative, matched-pairs design. Patients isolated due to methicillinResistant Staphylococcus aureus (MRSA) were matched with controls without MRSA infection admitted to a multi-bedded ward, based on: gender, injury level, injury severity (AIS grade), age at the time of injury and year of admission.

Objectives Determine the implications of MRSA-related infection isolation on spinal cord injury patients' anxiety, depression, appraisals of disability, perceived manageability and pain intensity. Hypotheses predicted patients who were isolated due to MRSA during inpatient stay would demonstrate poorer psychological health outcomes at discharge in comparison with non-isolated matched controls.

Setting National Spinal Injuries Centre, England, UK.

Methods Secondary analyses were conducted on pre-existing data based on patients' first admission for primary rehabilitation. Psychometric scales were used to measure outcome variables. Assessments were repeated at the time of admission and discharge.

Results Nonparametric longitudinal analyses using the nparLD package in $\mathrm{R}$ were conducted. Relative treatment effects demonstrated that there were no significant differences between groups across all outcome measures. There was a significant effect of time (admission vs discharge) on perceived manageability and pain intensity, indicating improved outcomes at discharge. There was no difference in the overall length of stay between the isolated and non-isolated groups.

Conclusions Isolation experienced by rehabilitation inpatients with spinal cord injury with MRSA had no effect on a series of psychological outcomes. Engaging with rehabilitation had a positive impact in reducing pain unpleasantness and increasing perceived manageability of spinal cord injury, irrespective of infection isolation.
\end{abstract}

\section{Introduction}

Methicillin-resistant Staphylococcus aureus (MRSA) is an antibiotic-resistant bacterium that is difficult to treat and easily transmitted with specific stigmatisation [1-4]. Patients with a spinal cord injury (SCI) are particularly at

Supplementary information The online version of this article (https:// doi.org/10.1038/s41394-020-0313-6) contains supplementary material, which is available to authorized users.

Jenna L. Gillett

bht.nsicpsychology@nhs.net

1 The University of Buckingham, Buckingham, Buckinghamshire, UK

2 National Spinal Injuries Centre, Stoke Mandeville Hospital, Buckinghamshire Healthcare NHS Trust, Aylesbury, UK risk for contracting MRSA [5, 6] often due to secondary complications including pressure sores and urinary tract infections [7-9]. National Institute for Health and Care Excellence (NICE) guidelines stipulate that infectioncontrol procedures in primary care are necessary to control spread and minimise MRSA impact [10, 11], but these can vary according to local guidance. Standard practice in the UK is to isolate patients in a single side room until they have three consecutive negative screens (see Box 1.1 for further MRSA infection-control guidelines as sourced via NICE [11] and the National Health Service (NHS) England [12]). Such measures effectively contain MRSA but can have potentially detrimental effects on patients' health outcomes [13], psychological wellbeing [14, 15] and social functioning $[16,17]$.

Patients who experience infection-isolation report feeling "more vulnerable" due to negative reactions from staff, family and other patients $\left[18^{\mathrm{p} 101}\right]$ in addition to 
feeling prevented from maintaining interpersonal relationships [18, 19]. Clinical care can be affected as isolation is associated with infrequent visits from healthcare staff $[20,21]$ and increased occurrence of preventable adverse events [22-24]. In addition, contact precautions impede patients' autonomy [25] that may have critical implications for SCI rehabilitation, as a person-centred approach is essential for rehabilitation [26]. Outcomes of isolation include high anger and frustration [14, 27, 28] anxiety and depression [29-31] and reduced quality of life [32]. Research demonstrates that infection-isolation results in longer length of overall inpatient stay [33, 34] and rehabilitation can be further limited by pragmatic factors, such as restricted access to group-based psychoeducation, a crucial component impacting rehabilitation $[35,36]$. Thus, strict contact precautions imposed on patients with MRSA can have potentially detrimental physical and psychosocial impacts on health and rehabilitation, compounded by severe stigmatisation and reduced patient autonomy [28, 37].

Despite evidence to suggest MRSA is a widespread complication in SCI rehabilitation currently, little research evaluates the explicit impact of such circumstances. Instead, the literature posits a broad focus on general hospital-acquired infections, including but not exclusively specifying MRSA [14, 27, 38, 39]. Given the significant societal stigmatisation of MRSA in the UK [1-4], there is a need to represent this demographic. The prevalence of MRSA in SCI rehabilitation is high, and the confounding implications of infection isolation and associated stigmatisation may predispose patients to poorer psychological outcomes. Thus, the purpose of this investigation is to determine whether MRSA-related isolation experienced by patients with SCI impacts psychological outcomes of rehabilitation. It is hypothesised that patients who were isolated due to positive MRSA screen(s) during inpatient rehabilitation will demonstrate poorer psychological health outcomes at discharge in comparison with non-isolated matched controls.

\section{Method}

\section{Design}

This study utilised a retrospective quantitative design wherein secondary data were analysed to determine the psychological outcomes of MRSA-isolated inpatients with SCI compared with matched controls who were not isolated without MRSA. A matched-pairs design was implemented to account for varying functionality level of SCI in accordance with previous protocol outlined by Kennedy and Hamilton [28].

\section{Participants}

The sample included 16 participants: eight inpatients who were isolated in a single side room due to present MRSA and eight matched controls in six to eight bedded bays without MRSA (see Table 1 for participant demographics). All participants were adults aged $18+$, admitted to a single SCI rehabilitation centre in the UK between 1 February 2015 and 31 May 2018. Matched-pairs design was based on previous SCI research methodology, in order to minimise high levels of medical and demographic variability between patients, which can impede between-groups comparability [28]. Patients were matched on the following characteristics: gender (exact match), level and grade of SCI as determined by standardised American Spinal Injuries Association Impairment Scale (AIS) [40] ( \pm 1 level), age at time of injury $( \pm 5$ years) and year of admission (exact match).

\section{Inclusion criteria for MRSA patients}

Acute SCI at the time of admission, presence of MRSA (either upon admission or developed during rehabilitation) resulting in an infection-isolation period between February 2015 and May 2018 and a Stoke Mandeville Spinal Needs Assessment Checklist (SMS-NAC) evaluation [41] completed within 2 weeks of admission and repeated at discharge.

\section{Inclusion criteria for control patients}

Acute SCI on admission, no recorded stay in infection isolation, an SMS-NAC evaluation completed within 2 weeks of admission and repeated at discharge.

\section{Excluded participants}

Participants with MRSA were excluded for the following reasons: suitable match unavailable due to injury demographics $(n=1)$, isolation/infection details unavailable on hospital record $(n=9)$, isolated for MRSA in a multibedded bay $(n=2)$ and SMS-NAC not completed at discharge $(n=15)$.

\section{Materials and measures}

The psychological health measures (anxiety, depression, appraisals of disability, perceived manageability) and pain intensity sections of the SMS-NAC [41] were used. The SMS-NAC is a patient-led, internationally recognised [42] and validated [43] comprehensive SCI outcome measure, administered at admission and discharge to assess verbal and physical skill acquisition and SCI knowledge [41]. 
Table 1 Participant demographics.

\begin{tabular}{|c|c|c|c|c|}
\hline Participant characteristics & MRSA-isolated group & Non-isolated matched controls & Total sample $(N=16)$ & Median, range ${ }^{a}$ \\
\hline Male, $n(\%)$ & $8(50)$ & $8(50)$ & $16(100)$ & \\
\hline Age at injury, mean (SD) & $60.1(8.9)$ & $60.6(6.9)$ & $60.4(7.7)$ & $60.5,45.5-71.6$ \\
\hline Time since injury (days), mean (SD) & $75.1(25.3)$ & $67.6(16.9)$ & $71.4(21.1)$ & $66,39-106$ \\
\hline Duration of stay (days), mean (SD) & $181.4(57.3)$ & $153.9(58.2)$ & $167.6(57.6)$ & $176.5,62-281$ \\
\hline \multicolumn{5}{|l|}{ Ethnicity, $n(\%)$} \\
\hline White British & $7(43.8)$ & $4(25)$ & $11(68.8)$ & \\
\hline Mixed: White and Black African & 0 & $1(6.3)$ & $1(6.3)$ & \\
\hline Asian or Asian British & 0 & $1(6.3)$ & $1(6.3)$ & \\
\hline Not stated & $1(6.3)$ & $2(12.5)$ & $3(18.8)$ & \\
\hline \multicolumn{5}{|l|}{ SCI level, $n(\%)$} \\
\hline Thoracic & $4(25)$ & $4(25)$ & $8(50)$ & \\
\hline Cervical & $3(18.8)$ & $3(18.8)$ & $6(37.5)$ & \\
\hline Lumbar & $1(6.3)$ & $1(6.3)$ & $2(12.5)$ & \\
\hline \multicolumn{5}{|l|}{ Mechanisms of SCI, $n(\%)$} \\
\hline $\begin{array}{l}\text { Road traffic accident (RTA) } \\
\text { Falls }\end{array}$ & $1(6.3)$ & $2(12.5)$ & $3(18.8)$ & \\
\hline Domestic & $2(12.5)$ & $1(6.3)$ & $3(18.8)$ & \\
\hline Self-harm (non-suicidal) & $1(6.3)$ & 0 & $1(6.3)$ & \\
\hline Non-traumatic injury & $4(25)$ & $4(25)$ & $8(50)$ & \\
\hline Other & 0 & $1(6.3)$ & $1(6.3)$ & \\
\hline \multicolumn{5}{|l|}{ Injury level and AIS rating, $n(\%)$} \\
\hline C1-4 with AIS A, B or C & $1(6.3)$ & $1(6.3)$ & $2(12.5)$ & \\
\hline C5-8 with AIS A, B or C & $1(6.3)$ & $1(6.3)$ & $2(12.5)$ & \\
\hline T1-S5 with AIS A, B or C & $4(25)$ & $4(25)$ & $8(50)$ & \\
\hline Any level with AIS D & $2(12.5)$ & $2(12.5)$ & $4(25)$ & \\
\hline
\end{tabular}

n.b. $\%$ are given to 1 decimal place and indicate $\%$ of whole sample $(N=16)$.

${ }^{\mathrm{a}}$ Median and range of whole sample $(N=16)$.

\section{Hospital anxiety and depression scale (HADS)}

The HADS [44] is regularly and reliably used in acute care [45]. The measure comprises of two subscales to measure anxiety and depression. The HADS has been highly credited with a mean Cronbach's alpha value of 0.82 to 0.83 [46] to indicate high internal validity [47].

\section{Appraisals of disability primary and secondary scale- short form (ADAPSS-SF)}

The ADAPSS-SF [48] is a self-evaluative measure of SCI impact and disability that is used to determine how patients perceive their own coping resources, the perceived adequacy of such resources and the likelihood that these can be employed effectively [49-51]. The measure comprises six items and has a 6-point Likert scale to measure how participants perceive their sense of disability in the context of their SCI. The measure is part of the UK NHS England SCI national dashboard for psychological outcomes with a Cronbach's alpha value of 0.83 [48].

\section{Perceived manageability}

The perceived manageability scale (PMnac) $[52,53]$ was developed to measure the extent to which patients feel they can personally manage their SCI, both physically and emotionally. The PMnac is based on the theory of planned behaviour, a psychological model that postulates behaviour is shaped by the interaction between attitudes, subjective norms and perceived sense of control [54]. The scale comprises of five items measured via a 4-point Likert scale. The PMnac is used in SCI quality of life research $[53,55,56]$ and has a Cronbach's alpha coefficient of 0.70 .

\section{Pain intensity}

Pain intensity ratings were recorded using a $0-10$ numerical rating scale with 0 indicated 'no pain' and 10 indicating 
'pain as bad as you can imagine' based on the last $24 \mathrm{~h}$. The measure is the most frequently used, validated brief assessments of pain in clinical research [57-59].

\section{Procedure}

Patients completed the SMS-NAC with a healthcare professional. SMS-NACs are administered within 2 weeks of admission and within 6 weeks prior to discharge. The SMSNAC is part of standardised treatment, with consent obtained from patients prior to completion. The research team conducted retrospective analyses on pre-existing SMS-NAC data and certify that all applicable institutional and governmental regulations were followed.

\section{Statistics and analyses}

Participants' total length of stay is indicated by the number of days elapsed between the date of admission and discharge SMS-NAC evaluation. Statistics were completed using $\mathrm{R}$ [60] with the package nparLD, which enables nonparametric longitudinal analyses [61, 62]. The betweengroups variable (patient group; MRSA-isolated vs nonisolated matched controls) and the within-groups variable (time; admission and discharge) were analysed to determine main and interaction effects on the outcome variables listed above. Relative treatment effect (RTE) was used as a measure of effect with the following interpretations: an RTE value lies between 0 and 1 , an RTE of 0.5 means no effect (a randomly selected participant from the whole sample has a 50/50 chance of achieving a lower score on an outcome measure than a randomly selected participant from either subgroup). An RTE $<0.5$ indicates a tendency for participants in a subgroup to score lower than a random participant from the whole sample, whereas an RTE $>0.5$ is indicative of a tendency for a participant to score higher than a randomly drawn subject from the whole group. The study utilises a nonparametric longitudinal design model, medians and interquartile ranges for the outcome variables are presented in Table 2 [63].

\section{Results}

Participants' demographics are presented in Table 1. There was no significant difference in overall length of inpatient stay between groups (MRSA-isolated vs non-isolated matched controls), $t(14)=0.96, p=0.36,95 \%$ CI $[-34.4,89.4]$.

\section{Anxiety and depression (HADS)}

The ANOVA-type test for anxiety revealed no significant main effect of group $\left(F_{(1, \infty)}=0.31, p=0.57\right.$; RTE $=0.46$
Table 2 Median and interquartile range (IQR) for all outcome measures.

\begin{tabular}{|c|c|c|}
\hline & MRSA-isolated group & Non-isolated group \\
\hline \multicolumn{3}{|c|}{ Anxiety (HADS-A) ${ }^{\mathrm{a}}$} \\
\hline Admission & $4(2.8)$ & $4.5(4.8)$ \\
\hline Discharge & $4(4.8)$ & $5.5(5.8)$ \\
\hline \multicolumn{3}{|c|}{ Depression (HADS-D) ${ }^{\mathrm{a}}$} \\
\hline Admission & $4(1.8)$ & $5(6.8)$ \\
\hline Discharge & $4(4.3)$ & $5.5(4.3)$ \\
\hline \multicolumn{3}{|c|}{ Appraisals of disability (ADAPSS-SF) ${ }^{\mathrm{a}}$} \\
\hline Admission & $15(16.5)$ & $15(19.3)$ \\
\hline Discharge & $21.5(15.5)$ & $16.5(7.5)$ \\
\hline \multicolumn{3}{|c|}{ Perceived manageability $(\mathrm{PMnac})^{\mathrm{b}}$} \\
\hline Admission & $15.5(3.5)$ & $13.5(5.5)$ \\
\hline Discharge & $16(5.3)$ & $17(6.3)$ \\
\hline \multicolumn{3}{|c|}{ Pain rating $(0-10 \mathrm{NRS})^{\mathrm{a}}$} \\
\hline Admission & $3.5(8)$ & $5.5(5)$ \\
\hline Discharge & $0(5.8)$ & $3(4.8)$ \\
\hline
\end{tabular}

${ }^{a}$ Higher score is indicative of worsened outcomes.

${ }^{\mathrm{b}}$ Higher score is indicative of improved outcomes.

for the MRSA-isolated group, 0.54 for the non-isolated group $)$ or time $\left(F_{(1, \infty)}=0.25, p=0.61 ; \mathrm{RTE}=0.49\right.$ for admission, 0.51 for discharge). The interaction was also non-significant: $F_{(1, \infty)}=2.65, p=0.1$; RTE $=0.41,0.51$ for the MRSA-isolated group at admission and discharge, respectively; $\mathrm{RTE}=0.57,0.51$ for the non-isolated group at admission and discharge, respectively, suggesting that anxiety was not affected by isolation status.

There were no significant effects for depression, for group $\left(F_{(1, \infty)}=1.5, p=0.22 ; \mathrm{RTE}=0.42\right.$ for MRSAisolated group, 0.58 for the non-isolated group), or for time $\left(F_{(1, \infty)}=0.01, \quad p=0.9 ; \quad \mathrm{RTE}=0.49\right.$ and 0.5 for admission and discharge, respectively). The interaction was non-significant $\left(F_{(1, \infty)}=0.81, p=0.37 ; \mathrm{RTE}=0.44,0.40\right.$ for the MRSA-isolated group at admission and discharge, respectively; $\mathrm{RTE}=0.55,0.61$ for the non-isolated group at admission and discharge, respectively) indicating that depression was comparable in the isolated and non-isolated groups.

\section{Appraisals of disability (ADAPSS-SF)}

Appraisals of disability showed no main effect of group $\left(F_{(1, \infty)}=0.0002, p=0.99 ; \mathrm{RTE}=0.50,0.50\right.$ for the MRSAisolated group and non-isolated group) and time $\left(F_{(1, \infty)}=\right.$ $0.81, p=0.37$; $\mathrm{RTE}=0.47,0.53$ for admission and discharge, respectively). There was no significant interaction $\left(F_{(1, \infty)}=0.41, p=0.52\right.$; RTE $=0.45,0.55$ for the MRSAisolated group at admission and discharge, respectively; $\mathrm{RTE}=0.49,0.51$ for the non-isolated group at admission 
and discharge, respectively). Both groups demonstrated comparable appraisals of their disability status.

\section{Perceived manageability (PMnac)}

For perceived manageability there was no main effect of group $\left(F_{(1, \infty)}=0, p=1\right.$; RTE $=0.5,0.5$ for the MRSAisolated group and non-isolated group). There was, however, a significant main effect whereby perceived manageability improved over time $\left(F_{(1, \infty)}=5.2, p=0.02\right.$; RTE $=$ $0.43,0.57$ for admission and discharge, respectively). There was no significant interaction $\left(F_{(1, \infty)}=1.49, p=0.22\right.$; RTE $=0.47,0.53$ for the MRSA-isolated group at admission and discharge, respectively; $\mathrm{RTE}=0.39,0.61$ for the nonisolated group at admission and discharge, respectively); therefore, both groups showed experienced improvements in perceived manageability during their rehabilitation and recovery.

\section{Pain intensity}

Overall, $75 \%$ of participants reported experiencing pain as a result of their SCI at the time of admission, whereas $56 \%$ patients reported experiencing pain at discharge, demonstrating $19 \%$ decrease. There was no main effect of group $(F=0.29, p=0.58$; $\mathrm{RTE}=0.47,0.53$ for the MRSA-isolated group, non-isolated group, respectively) but there was a significant main effect of time indicating improved pain scores at discharge $\left(F_{(1, \infty)}=5.11 ; p=0.02\right.$; $\mathrm{RTE}=0.58$ for admission $\mathrm{RTE}=0.42$ for discharge) . There was no significant interaction $\left(F_{(1, \infty)}=0.33, p=\right.$ 0.57 ; $\mathrm{RTE}=0.53,0.41$ for the MRSA-isolated group at admission and discharge, respectively; RTE $=0.64,0.43$ for the non-isolated group at admission and discharge, respectively).

\section{Discussion}

Results demonstrated no conclusive general psychological health outcome differences between patients who were isolated for MRSA in a single side room compared with non-isolated patients without MRSA. Perceived manageability of SCI and pain intensity outcomes improved over time in rehabilitation, irrespective of MRSA status, though it is important to consider the small variation in RTEs. There was no difference in the overall length of inpatient stay between the MRSA-isolated group and non-isolated matched controls.

It is possible that MRSA isolation had no main effect on psychological outcomes due to variability in patients' individual perceptions of isolation, perhaps in relation to the quality (rather than quantity) of social interactions which continued during isolation- $\mathrm{a}$ factor that was not assessed within the current investigation. Research distinguishes between feeling and being isolated and this is critical for patient experience and clinical implications; it is possible to experience being alone without simultaneously feeling lonely [64]. Thus, an important factor in shaping patients' isolation experiences is social capital-a protective mechanism found to insulate the individual from biopsychosocial stressors, bolstering psychological wellbeing via social connectedness [65]. Sources for such social capital and interaction can be ascertained via healthcare staff, hospital porters, visitors and other patients. Indeed, nurses have been found to offer both informational and emotional support to patients [66], which can provide sufficient interaction to protect against feeling lonely in isolation, potentially minimising negative psychological impact.

Notably, the quality of such social interaction, not necessarily the spread of social networks, impacts perceptions of loneliness and psychological health [67]; fewer, high-quality interactions can be more protective and foster enough social connectedness to buffer against anxiety, depression and loneliness [68]. Given the literature, the nonsignificant finding in the present study could therefore be due to a skilled staff providing additional emotional support. However, this was not controlled in the present study and needs to be evidenced further. There are potential implications for other infection-control settings, not just those relating to MRSA, particularly given the recent COVID-19 pandemic and associated imposed isolation experienced worldwide [69-71]. With this cohesive appreciation for social connectedness and the potential barriers incurred during imposed isolation [71, 72] healthcare staff, peers and relatives' perceptions of what it means to be isolated may lead to reduced stigmatisation and improved social connectedness.

The strength of therapeutic relationships should also be considered in explaining how patients' experiences of SCI rehabilitation are shaped [73]. A biopsychosocial approach to SCI rehabilitation has a strong evidence base [74, 75], incorporating multi-domain progress via physiotherapy [76], occupational therapy and clinical psychological therapy [77], goal planning [78] and psychosocial education $[36,75]$. As a result of this integrated approach, many individuals in the current study would have received some form of psychological intervention as a standard part of inpatient rehabilitation. During such therapeutic sessions any negative psychosocial effects of MRSA isolation will likely have been addressed (either directly or indirectly) by appropriate clinical intervention [77, 79]. This psychological support could have provided a robust defence against worsened outcomes of isolation, and therefore potentially explain why there were no differences in psychological measures between groups. 
Pain intensity and perceived manageability improved over time, demonstrating the positive impact of diverse and intense rehabilitation. SCI requires extensive adjustment $[49,55]$ and such adaptation requires support from multiple disciplines to provide a cohesive, manageable care plan for patients. Consequently, it can be inferred that a diverse, multi-faceted rehabilitation programme can have numerous health benefits for individuals with SCI including improved perceptions of manageability and coping post injury as well as in relation to pain outcomes.

The implications of MRSA isolation on overall length of stay during inpatient rehabilitation are potentially paramount. In the current study, there was no difference between the MRSA-isolated group and the non-isolated group in overall length of inpatient stay. However, one potential confounding variable was the amount of time spent in isolation, which has previously been related to longer overall hospitalisation [33, 34]. Average length of stay for SCI patients is diverse within the literature [80] spanning from 47 days in Russia [81] to 240 days in the Netherlands [82], with non-traumatic injury in the UK averaging 143 days [83]. Length of stay can implicitly impact rehabilitation outcomes $[33,84]$ and lead to reduced functional independence [85]. However, the evidence from the current study would argue that length of stay was not substantially longer than that of non-isolated matched controls and no detrimental impact on psychological health aspects was incurred by those who were isolated. This suggests that infection-isolation control protocols such as those outlined in Box 1.1, as employed within NHS England, remain valid and are unlikely to impede rehabilitation outcomes.

\section{Limitations}

This study is limited by small, specific sampling at a single site. Although the specialist SCI centre used in this study accepts adult patient referrals across $30 \%$ of England, the strict inclusion and exclusion criteria utilised in this study may limit the generalisability of findings. To minimise potential selection bias, the current research utilised a well-evidenced matched-pairs design [28], controlling for wide variation in injury-related demographics. The current study assessed a specific selection of psychological outcomes in accordance with the previous literature [56, 86]; however, future research could further interrogate the impact of infection isolation by assessing in greater depth a wider variety of biopsychosocial measures. A further limitation is the lack of controlling for variation in length of time spent in isolation relative to overall length of inpatient stay, which would naturally impact experiences of isolation [84]. Though this study intentionally focused on MRSA-related isolation specifically, the anticipated and felt social stigma of other infections [87, 88] and societal stigma variation worldwide [89] may differentially impact outcomes. Future research comparing rehabilitation experiences sampled across various sites with multiple infection-control protocols and durations would be highly beneficial to the literature and inform clinical practice.

\section{Conclusion}

The current study provides novel findings into the psychological outcomes of individuals with SCI who simultaneously experience MRSA-specific contact precautions. This article provides advocacy for an integrated, multidimensional approach to SCI rehabilitation to improve outcomes in perceived manageability and pain. Outcomes provide support for NHS England infection-control protocol for MRSA in primary care; as contrary to much literature, there were no detrimental effects on the psychological wellbeing of patients with SCI. Although the patients in this study did not experience isolation during the recent COVID-19 pandemic, the discussed factors in relation to the experiences of MRSA isolation may provide some parallels in clinical practice. This research may be a useful comparator and avenue for future study in relation to such variables of recent interest.

\section{Data availability}

The SMS-NAC is part of a standard clinical database that contains patient identifiable information. Pseudononymised data can be made available on reasonable request to Buckinghamshire Healthcare NHS Trust.

Acknowledgements Thanks to the patients and staff of the National Spinal Cord Injuries Centre, Stoke Mandeville Hospital, Buckinghamshire Healthcare NHS Trust, for completion of the standard clinical outcome tool of the SMS-NAC that facilitated this research. The authors are also grateful to Dr Anna Temp as well as Prof. Frank Konietschke and Prof. Edgar Brunner for assistance with data analysis and using the nparLD package.

Funding The University of Buckingham Postgraduate Conference Fund (PGCF) supported this study being presented at a UK Postgraduate Psychology Conference prior to publication by the corresponding author. No other financial sponsorship was obtained in relation to this study.

\section{Compliance with ethical standards}

Conflict of interest The authors declare that they have no conflict of interest.

Publisher's note Springer Nature remains neutral with regard to jurisdictional claims in published maps and institutional affiliations. 


\section{References}

1. Braut GS, Holt J. Meticillin-resistant Staphylococcus aureus infection-the infectious stigma of our time? J Hosp Infect. 2011;77:148-52.

2. Andersson H, Lindholm C, Fossum B. MRSA—global threat and personal disaster: patients' experiences. Int Nurs Rev. 2011;58:47-53. https://doi.org/10.1111/j.1466-7657.2010.00833.x.

3. Washer P, Joffe H. The "hospital superbug": social representations of MRSA. Soc Sci Med. 2006;63:2141-52.

4. Knifton C. Social work and the rise of the MRSA 'Super Bug'. Practice. 2005;17:39-42.

5. Hassouna H, Haq EU, Gall A. MRSA colonisation in spinal cord injury: Implications on patients rehabilitation. Acta Orthop Belg. 2008;74:528-30

6. Evans ME, Kralovic SM, Simbartl LA, Obrosky DS, Hammond MC, Goldstein B, et al. Prevention of methicillin-resistant Staphylococcus aureus infections in spinal cord injury units. Am J Infect Control. 2013;41:422-6.

7. Dana AN, Bauman WA. Bacteriology of pressure ulcers in individuals with spinal cord injury: what we know and what we should know. J Spinal Cord Med. 2015;38:147-60. http://www.ta ndfonline.com/doi/full/10.1179/2045772314Y.0000000234.

8. Joseph C, Nilsson Wikmar L. Prevalence of secondary medical complications and risk factors for pressure ulcers after traumatic spinal cord injury during acute care in South Africa. Spinal Cord. 2016;54:535-9. http://www.nature.com/articles/sc2015189.

9. Espejo E, Andrés M, Borrallo RM, Padilla E, Garcia-Restoy E, Bella F. Bacteremia associated with pressure ulcers: a prospective cohort study. Eur J Clin Microbiol Infect Dis. 2018;37:969-75. https://doi.org/10.1007/s10096-018-3216-8.

10. NICE. Infection, prevention and control of healthcare-associated infections in primary and community care (NICE guideline). In: Clinical Guidance 139. London: National Institute for Health and Clinical Excellence; 2012. https://www.nice.org.uk/guidance/cg139.

11. National Institute for Health and Care Excellence. Infection prevention and control quality standard (NICE Quality Standard No. 61). National Institute for Health and Care Excellence; 2014. https://www.nice.org.uk/guidance/qs61.

12. NHS England. Everyone counts: planning for patients $2014 / 15$ to 2018/19. NHS England; 2013. https://www.england.nhs.uk/wpcontent/uploads/2013/12/5yr-strat-plann-guid-wa.pdf.

13. Tran K, Bell C, Stall N, Tomlinson G, McGeer A, Morris A, et al. The effect of hospital isolation precautions on patient outcomes and cost of care: a multi-site, retrospective, propensity scorematched cohort study. J Gen Intern Med. 2017;32:262-8. https:// doi.org/10.1007/s11606-016-3862-4.

14. Abad C, Fearday A, Safdar N. Adverse effects of isolation in hospitalised patients: a systematic review. J Hosp Infect. 2010;76:97-102. http://www.ncbi.nlm.nih.gov/pubmed/20619929.

15. Rump B, de Boer M, Reis R, Wassenberg M, van Steenbergen J. Signs of stigma and poor mental health among carriers of MRSA. J Hosp Infect. 2017;95:268-74. http://www.ncbi.nlm.nih.gov/ pubmed/27789041.

16. Lindberg M, Carlsson M, Högman M, Skytt B. Suffering from meticillin-resistant Staphylococcus aureus: experiences and understandings of colonisation. J Hosp Infect. 2009;73:271-7. https://linkinghub.elsevier.com/retrieve/pii/S0195670109002916.

17. Krishnasamy R, Wilkinson CI, McClure CD, Wilson M, Bashford $\mathrm{J}$, Clark CJ, et al. Contact precautions for colonisation with multidrug-resistant organisms and haemodialysis patient quality of life and mood: a pilot case-control study. Ren Soc Australas J. 2019;15:12-25.

18. Skyman E, Sjöström HT, Hellström L. Patients experiences of being infected with MRSA at a hospital and subsequently source isolated. Scand J Caring Sci. 2010;24:101-7. http://search. ebscohost.com/login.aspx?direct $=$ true $\& \mathrm{db}=$ psyh\&AN $=2010$ 02781-013\&site $=$ ehost-live.

19. Barratt RL, Shaban R, Moyle W. Patient experience of source isolation: lessons for clinical practice. Contemp Nurse. 2011;39:180-93. https://www.researchgate.net/profile/Ruth_Barratt3/publication/ 224887266_Patient_experience_of_source_isolation_Lessons_for_ clinical_practice/links/56e62d1508aedb4cc8ae961f.pdf.

20. Morgan DJ, Pineles L, Shardell M, Graham MM, Mohammadi S, Forrest GN, et al. The effect of contact precautions on healthcare worker activity in acute care hospitals. Infect Control Hosp Epidemiol. 2013;34:69-73. https://www.cambridge.org/core/product/ identifier/S019594170003201X/type/journal_article.

21. Saint S, Higgins LA, Nallamothu BK, Chenoweth C. Do physicians examine patients in contact isolation less frequently? A brief report. Am J Infect Control. 2003;31:354-6.

22. Stelfox HT, Bates DW, Redelmeier DA. Safety of patients isolated for infection control. J Am Med Assoc. 2003;290:1899-905.

23. Karki S, Leder K, Cheng AC. Patients under contact precautions have an increased risk of injuries and medication errors a retrospective cohort study. Infect Control Hosp Epidemiol. 2013;34:1118-20.

24. Zahar JR, Garrouste-Orgeas M, Vesin A, Schwebel C, Bonadona A, Philippart F, et al. Impact of contact isolation for multidrugresistant organisms on the occurrence of medical errors and adverse events. Intensive Care Med. 2013;39:2153-60.

25. Vottero B, Rittenmeyer L. The hospitalised patients' experience of being in protective/source isolation: a systematic review of qualitative evidence. JBI Libr Syst Rev [Internet]. 2012;10:935-76. http://www.ncbi.nlm.nih.gov/pubmed/27820463.

26. Melin J, Persson L-O, Taft C, Kreuter M. Patient participation from the perspective of staff members working in spinal cord injury rehabilitation. Spinal Cord. 2018;56:614-20. http://www.na ture.com/articles/s41393-018-0061-7.

27. Gammon J, Hunt J, Musselwhite C. The stigmatisation of source isolation: a literature review. J Res Nurs. 2019;24:677-93.

28. Kennedy P, Hamilton LR. Psychological impact of the management of methicillin-resistant Staphylococcus aureus (MRSA) in patients with spinal cord injury. Spinal Cord. 1997;35:617-9. http://www.ncbi.nlm.nih.gov/pubmed/9300970.

29. Criddle P, Potter J. Exploring patients' views on colonisation with meticillin-resistant Staphylococcus aureus. Br J Infect Control. 2006;7:24-8. https://doi.org/10.1177/14690446060070020701.

30. Catalano G, Houston SH, Catalano MC, Butera AS, Jennings SM, Hakala SM, et al. Anxiety and depression in hospitalized patients in resistant organism isolation. South Med J. 2003;96:141-5.

31. Granzotto EM, Gouveia AM, Gasparetto J, Dantas LR, Tuon FF. Depression and anxiety in hospitalized patients on contact precautions for multidrug-resistant microorganisms. Infect, Dis Health. Forthcoming 2020. https://www.sciencedirect.com/ science/article/abs/pii/S246804512030002X.

32. Sharma A, Pillai DR, Lu M, Doolan C, Leal J, Kim J, et al. Impact of isolation precautions on quality of life: a meta-analysis. J Hosp Infect. 2020;105:35-42.

33. Andreassen AES, Jacobsen CM, de Blasio BF, White R, Kristiansen IS, Elstrøm P. The impact of methicillin-resistant S. aureus on length of stay, readmissions and costs: a register based casecontrol study of patients hospitalized in Norway. Antimicrob Resist Infect Control. 2017;6:1-8.

34. Macedo-Viñas M, de Angelis G, Rohner P, Safran E, Stewardson A, Fankhauser C, et al. Burden of meticillin-resistant Staphylococcus aureus infections at a Swiss University hospital: excess length of stay and costs. J Hosp Infect. 2013;84:132-7.

35. Li Y, Bressington D, Chien WT. Systematic review of psychosocial interventions for people with spinal cord injury during inpatient rehabilitation: implications for evidence-based practice. 
Worldviews Evidence-Based Nursing. 2017;14:499-506. http:// doi.wiley.com/10.1111/wvn.12238.

36. Hough S, Stone MT, Buse DC. Dating and relationship psychoeducational group for veterans with spinal cord injury/dysfunction: a historical account of an initial clinical course. Sex Disabil. 2013;31:337-59.

37. Tyler $\mathrm{C}$. The nursing management of MRSA on a spinal injuries unit. Br J Nurs. 1997;6:134-42.

38. Gammon J, Hunt J. Source isolation and patient wellbeing in healthcare settings. Br J Nurs. 2018;27:88-91. https://doi.org/10. 12968/bjon.2018.27.2.88.

39. Rump B, Timen A, Verweij M, Hulscher M. Experiences of carriers of multidrug-resistant organisms: a systematic review. Clin Microbiol Infect. 2019;25:274-9.

40. Kirshblum SC, Waring W, Biering-Sorensen F, Burns SP, Johansen M, Schmidt-Read M. et al. Reference for the 2011 revision of the international standards for neurological classification of spinal cord injury. J Spinal Cord Med. 2011;34:547-54. https://doi.org/10.1179/107902611X13186000420242.

41. Kennedy P, Hamilton LR. The needs assessment checklist: a clinical approach to measuring outcome. Spinal Cord. 1999;37:136-9.

42. Dawson J, Shamley D, Jamous MA. A structured review of outcome measures used for the assessment of rehabilitation interventions for spinal cord injury. Spinal Cord. 2008;46:768-80.

43. Berry C, Kennedy P, Hindson LM. Internal consistency and responsiveness of the skin management needs assessment checklist post-spinal cord injury. J Spinal Cord Med. 2004;27:63-71.

44. Zigmond AS, Snaith RP. The hospital anxiety and depression scale. Acta Psychiatr Scand. 1983;67:361-70. https://doi.org/10. 1111/j.1600-0447.1983.tb09716.x.

45. Turk DC, Dworkin RH, Trudeau JJ, Benson C, Biondi DM, Katz $\mathrm{NP}$, et al. Validation of the hospital anxiety and depression scale in patients with acute low back pain. J Pain. 2015;16:1012-21. https://www.sciencedirect.com/science/article/pii/ S1526590015007610.

46. Bjelland I, Dahl AA, Haug TT, Neckelmann D. The validity of the hospital anxiety and depression scale. An updated literature review. J Psychosom Res. 2002;52:69-77. http://www.ncbi.nlm. nih.gov/pubmed/11832252.

47. Nunnally JC. Psychometric theory. 2nd ed. New York: McGrawHill; 1978.

48. Dean RE, Kennedy P. Measuring appraisals following acquired spinal cord injury: a preliminary psychometric analysis of the appraisals of disability. Rehabil Psychol. 2009;54:222-31. http:// doi.apa.org/getdoi.cfm?doi=10.1037/a0015581.

49. Eaton R, Jones K, Duff J. Cognitive appraisals and emotional status following a spinal cord injury in post-acute rehabilitation. Spinal Cord. 2018. http://www.ncbi.nlm.nih.gov/pubmed/29895873.

50. Mignogna J, Christie AJ, Holmes SA, Ames H. Measuring disability-associated appraisals for veterans with spinal cord injury. Rehabil Psychol. 2015;60:99-104.

51. McDonald SD, Goldberg-Looney LD, Mickens MN, Ellwood MS, Mutchler BJ, Perrin PB. Appraisals of disability primary and secondary scale-short form (ADAPSS-sf): psychometrics and association with mental health among U.S. military veterans with spinal cord injury. Rehabil Psychol. 2018;63:372-82. http://www. ncbi.nlm.nih.gov/pubmed/30047748.

52. Sheppard R, Kennedy P, Mackey CA. Theory of planned behaviour, skin care and pressure sores following spinal cord injury. $\mathrm{J}$ Clin Psychol Med Settings. 2006;13:358-66.

53. Kennedy P, Scott-Wilson U, Sandhu N. The psychometric analysis of a brief and sensitive measure of perceived manageability. Psychol, Health Med. 2009;14:454-65. http://www.tandfonline. com/doi/full/10.1080/13548500903012848.
54. Ajzen I. The theory of planned behaviour: reactions and reflections. Psychol Health. 2011;26:1113-27. http://www.tandfonline. com/doi/abs/10.1080/08870446.2011.613995.

55. Kennedy P, Nolanc M, Smithsona E. Psychological adjustment to spinal cord injury in Ireland: quality of life, appraisals and coping. Ir J Psychol. 2011;32:116-29.

56. Wolstenholme D, Downes T, Leaver J, Partridge R, Langley J. Improving self-efficacy in spinal cord injury patients through "design thinking" rehabilitation workshops. BMJ Qual Improv Rep. 2014;3:u205728.w2340.

57. Nicholas MK, Asghari A, Blyth FM. What do the numbers mean? Normative data in chronic pain measures. Pain. 2008;134:158-73.

58. Williamson A, Hoggart B. Pain: a review of three commonly used pain rating scales. J Clin Nurs. 2005;14:798-804. http://doi.wiley. com/10.1111/j.1365-2702.2005.01121.x.

59. Ferreira-Valente MA, Pais-Ribeiro JL, Jensen MP. Validity of four pain intensity rating scales. Pain. 2011;152:2399-404.

60. R Core Team. R: a language and environment for statistical computing. Vienna, Austria: R Core Team; 2013. http://www.Rproject.org/.

61. Noguchi K, Gel YR, Brunner E, Konietschke F. nparLD: an R software package for the nonparametric analysis of longitudinal data in factorial experiments. J Stat Softw. 2012;50:1-23.

62. Brunner E, Domhof S, Langer F. Nonparametric analysis of longitudinal data in factorial experiments. New York: John Wiley \& Sons; 2002.

63. Mishra P, Pandey C, Singh U, Gupta A, Sahu C, Keshri A. Descriptive statistics and normality tests for statistical data. Ann Card Anaesth. 2019;22:67. http://www.annals.in/text.asp?2019/ 22/1/67/250184.

64. Karnick PM. Feeling lonely: theoretical perspectives. Nurs Sci Q. 2005;18:7-12.

65. Kawachi I, Berkman LF. Social ties and mental health. J Urban Health. 2001;78:458-67. http://www.ncbi.nlm.nih.gov/pubmed/ 11564849.

66. Mattila E, Kaunonen M, Aalto P, Åstedt-Kurki P. The method of nursing support in hospital and patients' and family members' experiences of the effectiveness of the support. Scand J Caring Sci. 2014;28:305-14. https://doi.org/10.1111/scs.12060.

67. Fiorillo D, Sabatini F. Quality and quantity: the role of social interactions in self-reported individual health. Soc Sci Med. 2011;73:1644-52. https://www.sciencedirect.com/science/article/ pii/S0277953611005636.

68. Taylor CT, Pearlstein SL, Kakaria S, Lyubomirsky S, Stein MB. Enhancing social connectedness in anxiety and depression through amplification of positivity: preliminary treatment outcomes and process of change. Cogn Ther Res. 2020;44:1-13.

69. Wilder-Smith A, Freedman DO. Isolation, quarantine, social distancing and community containment: pivotal role for old-style public health measures in the novel coronavirus (2019-nCoV) outbreak. J Travel Medicine. 2020;27:1-4. https://academic.oup. com/jtm/article-abstract/27/2/taaa020/5735321.

70. Usher K, Bhullar N, Jackson D. Life in the pandemic: social isolation and mental health. J Clin Nurs. 2020. https://onlinelibra ry.wiley.com/doi/abs/10.1111/jocn.15290.

71. Pfefferbaum B, North CS. Mental health and the Covid-19 pandemic. N Engl J Med [Internet]. 2020 [cited 2020 May 28]:1-3. https://www.nejm.org/doi/full/10.1056/NEJMp2008017.

72. Torales J, O'Higgins M, Castaldelli-Maia JM, Ventriglio A The outbreak of COVID-19 coronavirus and its impact on global mental health. Int J Soc Psychiatry. 2020. http://journals.sagepub. com/doi/10.1177/0020764020915212.

73. Gelso C. A tripartite model of the therapeutic relationship: theory, research, and practice. Psychother Res. 2014;24:117-31. http:// www.tandfonline.com/doi/abs/10.1080/10503307.2013.845920. 
74. Derakhshanrad N, Vosoughi F, Yekaninejad MS, Moshayedi P, Saberi H. Functional impact of multidisciplinary outpatient program on patients with chronic complete spinal cord injury. Spinal Cord. 2015;53:860-5. http://www.nature.com/articles/sc2015136.

75. Kamper SJ, Apeldoorn AT, Chiarotto A, Smeets RJEM, Ostelo RWJG, Guzman J, et al. Multidisciplinary biopsychosocial rehabilitation for chronic low back pain: Cochrane systematic review and meta-analysis. BMJ. 2015;350:h444. http://www.ncbi.nlm. nih.gov/pubmed/25694111.

76. Harvey LA. Physiotherapy rehabilitation for people with spinal cord injuries. J Physiother. 2016;62:4-11. https://www. sciencedirect.com/science/article/pii/S1836955315001307.

77. Kennedy P, Kilvert A, Hasson L. A 21-year longitudinal analysis of impact, coping, and appraisals following spinal cord injury. Rehabil Psychol. 2016;61:92-101. http://doi.apa.org/getdoi.cfm? doi $=10.1037 /$ rep0000066.

78. Duff J, Evans MJ, Kennedy P. Goal planning: a retrospective audit of rehabilitation process and outcome. Clin Rehabil.2004;18:275-86. https://doi.org/10.1191/0269215504cr720oa.

79. Razai MS, Oakeshott P, Kankam H, Galea S, Stokes-Lampard H. Mitigating the psychological effects of social isolation during the covid-19 pandemic. BMJ. 2020;369(m1904):1-5.

80. Burns AS, Santos A, Cheng CL, Chan E, Fallah N, Atkins D, et al. Understanding length of stay after spinal cord injury: insights and limitations from the access to care and timing project. J Neurotrauma. 2017;34:2910-6.

81. Fromovich-Amit Y, Biering-Sørensen F, Baskov V, Juocevicius A, Hansen HV, Gelernter I, et al. Properties and outcomes of spinal rehabilitation units in four countries. Spinal Cord. 2009;47:597-603.
82. Post MW, van der Woude LH. Duration and functional outcome of spinal cord injury rehabilitation in the Netherlands $\mathrm{PhD}$ project low-intensity wheelchair training for inactive people with longterm spinal cord injury view project Swiss Spinal Cord Injury Cohort Study View project. J Rehabil Res Dev. 2005;42:75-86. www.fbw.vu.nl/onderzoek/A4zon/ZONenglish.

83. New PW, Reeves RK, Smith É, Townson A, Eriks-Hoogland I, Gupta A, et al. International retrospective comparison of inpatient rehabilitation for patients with spinal cord dysfunction epidemiology and clinical outcomes. Arch Phys Med Rehabil. 2015;96:1080-7.

84. Wassenberg MWM, Severs D, Bonten MJM. Psychological impact of short-term isolation measures in hospitalised patients. $\mathrm{J}$ Hosp Infect. 2010;75:124-7.

85. Mahmoud H, Qannam H, Zbogar D, Mortenson B. Spinal cord injury rehabilitation in Riyadh, Saudi Arabia: time to rehabilitation admission, length of stay and functional independence. Spinal Cord. 2017;55:509-14.

86. Kennedy P, Kilvert A, Hasson L. Ethnicity and rehabilitation outcomes: the needs assessment checklist. Spinal Cord. 2015;53:334-9.

87. Valizadeh L, Zamanzadeh V, Bayani M, Zabihi A. The social stigma experience in patients with hepatitis B infection: a qualitative study. Gastroenterol Nurs. 2017;40:143-50.

88. Pacheco M, Spyropoulos V, Caron I. The experience of source isolation for Clostridium difficile in adult patients and their families. Can J Infect Control. 2010;25:166-74.

89. Eklund M, Wannberg E, Herlitz J. Registered nurses' experience of caring for patients suffering from MRSA in the Philippines [Batchelor's thesis on the internet]. Sweden, DiVa: University of Borås; 2019 [cited 2020 Jun 7]. https://www.diva-portal.org/sma sh/record.jsf?pid=diva2\%3A1392133\&dswid $=9495$. 